\title{
Classification of ITU Recommendations and Reports Base on IMT-2020 High Frequency Candidate Band EMC Analysis
}

\author{
Zhaojun Qian', Bo Li², Long Kang3 ${ }^{3}$ Tan Wang1*, Weidong Wang² \\ ${ }^{1}$ The State Radio Monitoring Center, Beijing, China \\ ${ }^{2}$ Beijing University of Posts and Telecommunications, Beijing, China \\ ${ }^{3}$ North China Electric Power University, Beijing, China \\ Email: qianzhaojun@srrc.org.cn, libo1993@bupt.edu.cn, 1243792870@qq.com, ${ }^{*}$ wangtan@srrc.org.cn, \\ wangweidong@bupt.edu.cn
}

How to cite this paper: Qian, Z.J., Li, B. Kang, L., Wang, T. and Wang, W.D. (2017) Classification of ITU Recommendations and Reports Base on IMT-2020 High Frequency Candidate Band EMC Analysis. Int. J. Communications, Network and System Sciences, 10, 163-169.

https://doi.org/10.4236/ijens.2017.105B016

Received: April 5, 2017

Accepted: May 23, 2017

Published: May 26, 2017

\begin{abstract}
This paper introduced ITU-R TG 5/1 task group, as well as the current research situation, especially illustrated some interference scenario. Based on $5 \mathrm{G}$ high frequency candidate band, radio communication services and the electromagnetic compatibility analysis work, we studied all recommendations and reports related to candidate sub bands, and then classified three very important sub-bands' recommendations and reports, which had played a positive role in promoting $5 \mathrm{G}$ high-frequency candidate band radio interference coexistence analysis research.
\end{abstract}

\section{Keywords}

IMT-2020, Candidate Band, Recommendations, Reports, Classification

\section{Introduction}

With the trend of globalizing of radio communication technology, almost all the counties focus on the international standardization of the technology. As an international standard in the world, the recommendations and reports from the International Telecommunication Union (ITU) is widely recognized, which are formulated by the ITU Radio communication sector (ITU-R) and stated by ITU members. Except the recommendations [1] cited in the Radio Regulation, others are not required to be carried out by the member countries. However, as ITU recommendations and reports are made by administrations, radio communication operators, equipment manufacturers and other relevant organizations' experts from all over the world, the recommendations and reports have extremely 
high execution validity and are carried out by countries around the world more and more commonly.

There are thousands of recommendations and reports, covering all aspects of radio services. Therefore, it is difficult for the researchers to understand these recommendations and reports one by one and chose the appropriate proposal, which will affect the application of it. In order to facilitate better understanding and using of these recommendations and reports for experts, scholars and engineers who are engaged in electromagnetic compatibility analyze research as well as to fully play the guidance role. Based on $5 \mathrm{G}$ high frequency candidate band, radio communication services and the electromagnetic compatibility analysis work, we made statistical analysis and classified partial recommendations and reports related to $5 \mathrm{G}$ high frequency candidate sub-bands, which has a positive role in promoting $5 \mathrm{G}$ high-frequency candidate band radio interference coexistence analysis research.

\section{ITU-R TG 5/1 Task Group}

TG 5/1 is a special task group under ITU-R SG 5 (Terrestrial services) [2] [3], taking responsible for WRC-19 Agenda Item 1.13 "conducting the sharing and compatibility studies, in accordance with Resolution 238 [COM6/20] (WRC 15), to consider identification of frequency bands for the future development of International Mobile Telecommunications (IMT), including possible additional allocations to the mobile service on a primary basis". Studies [4] on frequency-related matters for International Mobile Telecommunications identification including possible additional allocations to the mobile services on a primary basis in portion(s) of the frequency range between 24.25 and $86 \mathrm{GHz}$ for the future development of International Mobile Telecommunications for 2020 and beyond.

\section{ITU-R TG 5/1 Current Research Situation}

The first meeting of the ITU-R TG5/1 task group was held in Geneva, Switzerland, on May 2016 23-25. All participant countries and organizations had been positive involved in the research work [5]-[10], relevant to the task group organization structure, management team election and work plan and so on. The meeting mainly aimed at the research content, especially in EMC analysis between IMT-2020 and other services. The candidate frequency band EMC research work was distributed into three working groups simultaneously: WG2-30 GHz (including 24.25-27.5 GHz, 31.8-3.4 GHz band), WG3-40/50 GHz (including 37-40.5 GHz, $40.5-42.5 \mathrm{GHz}, 42.5-43.5 \mathrm{GHz}, 45.5-47 \mathrm{GHz}, 47-47.2 \mathrm{GHz}$, 47.2-50.2 GHz, 50.4-52.6 GHz band), and WG4-70/80 GHz (including 66-76 $\mathrm{GHz}, 81-86 \mathrm{GHz}$ band).

The main responsibilities of ITU-R TG $5 / 1$ task group is to determine technical characteristics of existing services including protection criterion in the $5 \mathrm{G}$ candidate bands or adjacent bands. Therefore it is necessary to carry out a lot of analysis of the inter service protection criterion in these frequency bands. The research mainly focuses on the following radio interference scenarios (see Table 
1). These research works would be completed in the next 2 to 3 years, and submitted to the WRC-19 for consideration.

\section{Classification of Recommendations and Reports}

\subsection{Introduction of Recommendations and Reports}

The Report is a technical, operational or procedural statement, prepared by a Study Group on a given subject related to a current Question or the results of studies [9]. The ITU-R Recommendations constitute a set of international technical standards developed by the Radio communication Sector (formerly CCIR) of the ITU [1]. According to different research areas, the ITU-R Recommendations are divided into 16 series and the ITU-Reports are divided into 13 series. In these reports, satellite news gathering, time signals and frequency standards emissions, vocabulary and related subjects series are not involved. Each series corresponds to the fixed study group (see Table 2).

Table 1. Focus on the study of radio interference scenarios.

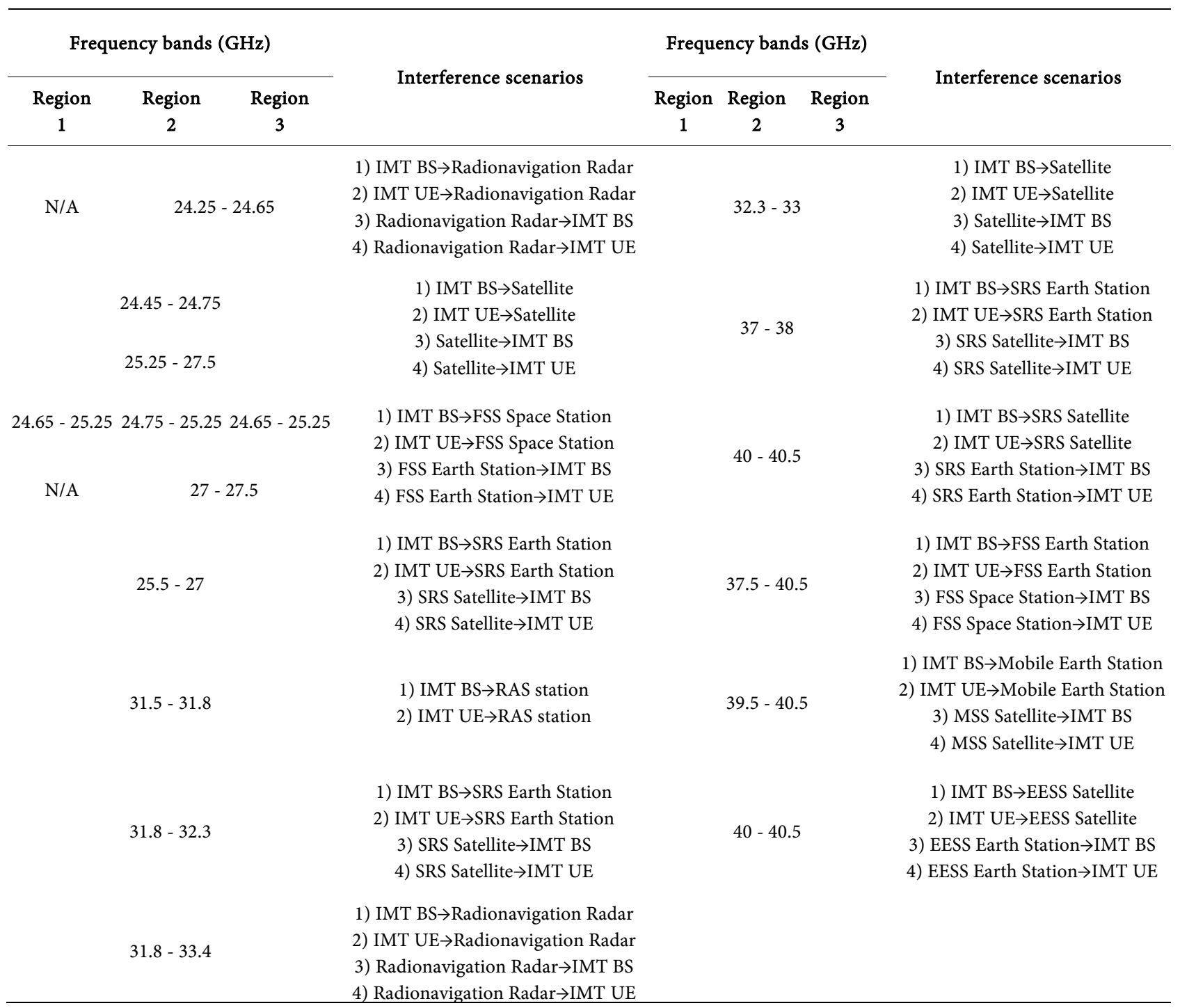


Table 2. Corresponding table between series of recommendations or reports and study group.

\begin{tabular}{|c|c|}
\hline Study Group & Series of recommendations or reports \\
\hline SG1 & SM series-Spectrum Management \\
\hline \multirow[t]{3}{*}{ SG3 } & P series-Radio Propagation \\
\hline & S series-Fixed-satellite service \\
\hline & SNG series-Satellite news gathering \\
\hline \multirow[t]{3}{*}{ SG4 } & $\begin{array}{l}\text { SF series-Frequency sharing and coordination between fixed-satellite and } \\
\text { fixed service systems }\end{array}$ \\
\hline & M series-Mobile, radio determination, amateur and related satellite services \\
\hline & BO series-Satellite delivery \\
\hline \multirow[t]{2}{*}{ SG5 } & F series-Fixed service \\
\hline & BS series-Broadcasting service (sound) \\
\hline \multirow{4}{*}{ SG6 } & BT series-Broadcasting service (television) \\
\hline & $\begin{array}{l}\text { BR series- } \text { Recording for production, archival and } \\
\text { play-out; film for television }\end{array}$ \\
\hline & RS series-Remote sensing systems \\
\hline & TF series-Time signals and frequency standards emissions \\
\hline \multirow[t]{3}{*}{ SG7 } & SA series-Space applications and meteorology \\
\hline & RA series-Radio astronomy \\
\hline & V series-Vocabulary and related subjects \\
\hline
\end{tabular}

\subsection{Statistical of Recommendations and Reports Relevant to 5G High Frequency Candidate Bands EMC Analysis}

In this paper, we classified the $5 \mathrm{G}$ high frequency candidate bands according to the frequency bands and the service features. Figure 1 shows the number of recommendations and reports in different frequency bands, where horizontal coordinates represent the frequency bands, and the longitudinal coordinates represent the number of recommendations and reports. Some recommendations and reports were used repeatedly in different frequency bands.

\subsection{Classification of Recommendations and Reports}

Based on above discussion, it is clarified that doing EMC analysis in this candidate sub-band is of more importance than other sub-band. PT1 ECC has been a primary research and we focus on the frequency bands of $24.25-27.5 \mathrm{GHz}, 31.8$ - 33.4 GHz and 40.5 - 42.5 GHz. Many countries may do EMC analysis first in this sub-band. So in this paper, we only show the classification of recommendations and reports in this sub-band due to page restricted (Tables 3-5).

\section{Conclusion}

In this paper, we introduced ITU-R TG 5/1 task group, as well as the current research situation. Based on $5 \mathrm{G}$ high frequency candidate band, radio communi- 
Table 3. 24.25 - 27.5 GHz sub-band recommendations and reports.

\begin{tabular}{|c|c|c|c|}
\hline Radio Communication Services & Sub-band $(\mathrm{GHz})$ & Rec Number & Rep Number \\
\hline Fixed & $24.25-27.5$ & SA.1276 & $\begin{array}{l}\text { F. } 2108 \\
\text { S. } 2150\end{array}$ \\
\hline \multirow[t]{2}{*}{$\begin{array}{l}\text { Fixed-Satellite } \\
\text { (Earth-to-Space) }\end{array}$} & \multirow[t]{2}{*}{$\begin{array}{c}24.65-25.25 \\
27-27.5\end{array}$} & S.1063 & $\begin{array}{l}\text { S.2223 } \\
\text { S.2261 }\end{array}$ \\
\hline & & S.1323 & S.2362 \\
\hline Inter-Satellite & $25.25-27.5$ & $\begin{array}{l}\text { F.1509 } \\
\text { SA.1415 }\end{array}$ & \\
\hline Time Signals and Frequency Standards Emissions & $25.25-27$ & TF.374 & \\
\hline \multirow[t]{2}{*}{$\begin{array}{l}\text { Earth Exploration-Satellite } \\
\quad \text { (Space-to-Earth) }\end{array}$} & \multirow[t]{2}{*}{$25.5-27$} & $\begin{array}{l}\text { SA. } 1862 \\
\text { SA. } 1027\end{array}$ & \\
\hline & & SA.1862 & SA. 2277 \\
\hline $\begin{array}{l}\text { Space Research } \\
\text { (Space-to-Earth) }\end{array}$ & $25.5-27$ & SA.1415 & $\begin{array}{l}\text { SA. } 2166 \\
\text { SA. } 2167 \\
\text { SA. } 2177 \\
\text { SA. } 2183\end{array}$ \\
\hline \multirow{8}{*}{$\begin{array}{c}\text { Fixed } \\
\text { Mobile } \\
\text { Fixed-Satellite } \\
\text { (Earth-to-Space) }\end{array}$} & \multirow{8}{*}{$27.5-28.5$} & F.748 & F. 2108 \\
\hline & & F.1609 & S. 2150 \\
\hline & & F.1607 & S. 2223 \\
\hline & & F.1569 & S.2261 \\
\hline & & $\begin{array}{l}\text { S.1063 } \\
\text { S.1323 }\end{array}$ & \\
\hline & & S.1431 & S. 2362 \\
\hline & & SF.1719 & \\
\hline & & SF.1601 & \\
\hline
\end{tabular}

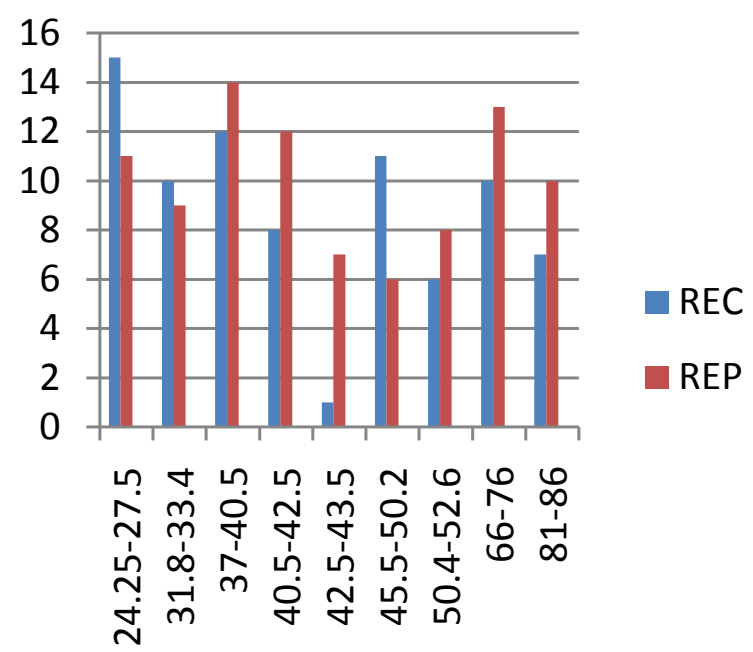

Figure 1. Classification statistics for recommendations and reports in sub-bands. 
Table 4. 31.8 - 33.4 GHz sub-band recommendations and reports.

\begin{tabular}{|c|c|c|c|}
\hline Radio Communication Services & Sub-band $(\mathrm{GHz})$ & Rec Number & Rep Number \\
\hline \multirow{7}{*}{$\begin{array}{c}\text { Earth Exploration-Satellite } \\
\text { (passive), Radio Astronomy, } \\
\text { Space Research(passive), [fixed], [Mobile] }\end{array}$} & \multirow{7}{*}{$31.5-31.8$} & \multirow{7}{*}{ F. 1570} & RA.2126 \\
\hline & & & RA. 2188 \\
\hline & & & SA. 2166 \\
\hline & & & SA. 2167 \\
\hline & & & SA. 2177 \\
\hline & & & SA. 2183 \\
\hline & & & RS. 2260 \\
\hline \multirow{3}{*}{ Fixed } & \multirow{3}{*}{$31.8-33.4$} & F. 1765 & F. 2108 \\
\hline & & F.1571 & \multirow{2}{*}{ S.2150 } \\
\hline & & F.1520 & \\
\hline \multirow{4}{*}{$\begin{array}{c}\text { Space Research (deep space) } \\
\text { (Space-to-Earth) }\end{array}$} & \multirow{4}{*}{$31.8-33.4$} & M.1466 & SA.2166 \\
\hline & & SA.1811 & SA.2167 \\
\hline & & \multirow{2}{*}{ SA.1157 } & SA.2177 \\
\hline & & & SA. 2183 \\
\hline Radiodetermination & $31.8-33.4$ & M.1466 & \\
\hline \multirow{2}{*}{ Inter-Satellite } & \multirow{2}{*}{$32.3-33$} & S.1151 & \\
\hline & & S.1591 & \\
\hline Radiodetermination & $33.4-34.2$ & M.1640 & \\
\hline
\end{tabular}

Table 5. 40.5 - 42.5 GHz sub-band recommendations and reports.

\begin{tabular}{|c|c|c|c|}
\hline Radio Communication Services & Sub-band (GHz) & Rec Number & Rep Number \\
\hline \multirow{3}{*}{$\begin{array}{c}\text { Earth Exploration-Satellite } \\
\text { (Earth-to-Space), Fixed, Mobile, } \\
\text { Mobile-Satellite }\end{array}$} & \multirow{7}{*}{$40-40.5$} & & F. 2108 \\
\hline & & & \\
\hline & & & S.2150 \\
\hline \multirow{3}{*}{$\begin{array}{l}\text { (Space-to-Earth), Space Research } \\
\text { (Earth-to-Space), } \\
\text { Fixed-Satellite(Space-to-Earth) }\end{array}$} & & & SA. 2166 \\
\hline & & & \\
\hline & & & SA.2177 \\
\hline Radiodetermination & & & SA. 2183 \\
\hline \multirow[b]{2}{*}{ Fixed } & \multirow[b]{2}{*}{$40.5-42.5$} & F.2005 & F. 2108 \\
\hline & & F.1669 & S. 2150 \\
\hline \multirow{4}{*}{ Fixed-Satellite (Space-to-Earth) } & \multirow{2}{*}{$40.5-42.5$} & F. 2005 & \multirow{2}{*}{ S.2150 } \\
\hline & & & \\
\hline & \multirow{5}{*}{$40.5-42.5$} & \multirow{5}{*}{ BO.1659 } & BO. 215 \\
\hline & & & BO.2016 \\
\hline \multirow[t]{4}{*}{ Broadcasting-Satellite } & & & BO.2071 \\
\hline & & & BO. 473 \\
\hline & & & BO.631 \\
\hline & \multirow{6}{*}{$42.5-43.5$} & RA.1031 & RA.2126 \\
\hline \multirow{5}{*}{$\begin{array}{c}\text { Fixed, } \\
\text { Fixed-Satellite } \\
\text { (Earth-to-Space), } \\
\text { Mobile, } \\
\text { Radio Astronomy }\end{array}$} & & RA.314 & RA. 2188 \\
\hline & & RA.517 & F. 2108 \\
\hline & & RA 611 & \\
\hline & & & S.2150 \\
\hline & & F. 2005 & \\
\hline
\end{tabular}


cation services and the electromagnetic compatibility analysis work, we statistically analyzed all recommendations and reports relevant to candidate sub-bands, and then classified three very important sub-bands' recommendations and reports in three very important sub-bands, which had played a positive role in promoting 5G high-frequency candidate band radio interference coexistence analysis research.

\section{Acknowledgements}

This work is supported by the National Science and Technology Major Project under Grants No. 2015ZX03002008, National High-tech R\&D Program (863 Program) under Grants No. 2014AA01A706.

\section{References}

[1] http://www.itu.int/pub/R-REC

[2] ITU-R Study Groups (2013) ITU-R Handbook.

[3] CPM19-1 Decision on the Establishment and Terms of Reference of Study Group 5 Task Group 5/1 (TG 5/1) on WRC-19 Agenda Item 1.13, 2015.

[4] Results of the First Session of the Conference Preparatory Meeting for WRC-19 (CPM19 1) (CPM19-1), ITU-R 2015.

[5] Japan. Considerations on Working Method of Task Group 5/1. ITU-R Document 5-1/1-E, May 2016.

[6] U.K. Organization of Itu-R Tg5/1 for the Preparation of the Studies Relevant to AI 1.13 of WRC-19. ITU-R Document 5-1/2-E, May 2016.

[7] China. Proposed Work Method and Work Plan for Task Group 5/1 on Agenda Item 1.13. ITU-R Document 5-1/6-E, May 2016.

[8] China. Down Selection the Sharing and Compatibility Study Scenarios on WRC-19 Agenda Item 1.13. ITU-R Document 5-1/7-E, May 2016.

[9] Brazil. Proposal for Organisation of the Work within Itu-R Tg5/1 for the Preparation of the Studies Relevant to WRC-19 AI 1.13. ITU-R Document 5-1/9-E, May 2016.

[10] Canada. Considerations on the Working Methods within Task Group 5/1. ITU-R Document 5-1/10-E, May 2016. 
Submit or recommend next manuscript to SCIRP and we will provide best service for you:

Accepting pre-submission inquiries through Email, Facebook, LinkedIn, Twitter, etc. A wide selection of journals (inclusive of 9 subjects, more than 200 journals)

Providing 24-hour high-quality service

User-friendly online submission system

Fair and swift peer-review system

Efficient typesetting and proofreading procedure

Display of the result of downloads and visits, as well as the number of cited articles Maximum dissemination of your research work

Submit your manuscript at: http://papersubmission.scirp.org/

Or contact ijens@scirp.org 